Reprod. Nutr. Dévelop., 1986, 26 (6), 1305-1317.

\title{
Effects of ecdysone injection on diapause termination in Pieris brassicae pupae. Evidence for a stimulatory action on endogenous ecdysone production
}

\author{
Martine ARPAGAUS, P. BEYDON, R. LAFONT
}

Laboratoire de Zoologie (CNRS UA 686), Ecole Normale Supérieure, 46, rue d'ULM, 75230 Paris Cedex 05, France.

Summary. Injection of ecdysone can break diapause in Pieris brassicae pupae. The purpose of this study was to investigate whether the injected hormone acts directly on the target tissues, promoting adult morphogenesis, or through a reactivation of the neuroendocrine system, leading to a neosynthesis of ecdysone. A dose of $500 \mathrm{ng} / \mathrm{pupa}$ was sufficient to obtain synchronous adult development. Ecdysone injected either in whole or in decapitated pupae induced a neosynthesis of ecdysone, starting on day 5 after treatment, and the onset of imaginal development. Thus, we suggest that ecdysone can act independently of the brain, and that its stimulatory action on ecdysone neosynthesis is probably indirect, according to the long delay (5 days) necessary for this reactivation. In addition, isolated abdomens from diapausing pupae injected with the same dose of ecdysone also developed, but did not synthesize any ecdysteroid. This suggests that the injected hormone has also a direct morphogenetic effect on target tissues. The significance of this ecdysone neosynthesis is discussed.

\section{Introduction.}

The development of many Insect species can be delayed in response to environmental conditions : this diapause state is a strategy for surviving during unfavourable climatic conditions. The white cabbage butterfly, Pieris brassicae (Lepidoptera) presents such an arrest of development at the pupal stage, induced by short photoperiods (L 8 : D 16, for example) during the fourth and early fifth larval stages (Claret, 1972).

The pupal diapause appears to be due to a deficiency of the circulating moulting hormones: ecdysone (E) and 20-hydroxyecdysone (20E) (Williams, 1946; Williams, 1952). In non-diapausing animals, $E$ is synthesized by the prothoracic glands (Chino et al., 1974 ; King et al., 1974) and released in the hemolymph. It is then hydroxylated in peripheral tissues into $20 \mathrm{E}$ (King and Sidall, 1969 ; Bergamasco and Horn, 1980) which is generally considered as the active

Correspondence should be sent to : Martine Arpagaus, Laboratoire de Zoologie, Ecole Normale Supérieure, 46, rue d’Ulm, 75230 Paris Cedex 05, France. 
moulting hormone. The main regulation of $E$ production is operated via a cerebral neuropeptide, the prothoracicotropic hormone (PTTH) which stimulates the prothoracic glands to synthesize and release the hormone (Bollenbacher et al., 1979). Thus, the classical scheme of the endocrine regulation of pupal diapause is that the brain controls the arrest of development by a lack of PTTH secretion (Williams, 1952) which in turn prevents the synthesis and release of $E$ by the prothoracic glands in diapausing pupae.

Indeed, it is possible to experimentally terminate diapause by injecting $E$ (Williams, 1968) or 20E (Bradfield and Denlinger, 1980; Bodnaryk, 1985). Therefore, diapausing pupae, which have very low levels of moulting hormone (5 $\mathrm{mg} / \mathrm{ml}$ in Hyalophora cecropia, Mc Daniel, 1979) constitute a favourable model to study the mechanism of action of these hormones on the onset of development. In fact, it is not clear whether the injected hormone acts directly on the target tissues to promote morphogenesis or if it acts through a reactivation of the animal's neuroendocrine system.

In the present report, we studied this question using ecdysone-stimulated diapausing pupae of Pieris brassicae. We analyzed the fate of the injected hormone as well as the neosynthesis of $E$ from injected $\left({ }^{3} \mathrm{H}\right)$ cholesterol.

Our results suggest that, in diapausing pupae of Pieris brassicae, the injected hormone has a double action : (1) it exerts a direct morphogenetic effect on target tissues, (2) it induces a neosynthesis of endogenous $E$, independently of the brain.

\section{Material and methods.}

Animals. - Larvae of the white cabbage butterfly (Pieris brassicae) were reared on a natural diet at $19^{\circ} \mathrm{C}$ under a short-day photoperiod ( $\mathrm{L}: 15 \mathrm{D}$ ). Under these conditions, all larvae develop into diapausing pupae. We used only male diapausing pupae, in order to obtain a better synchronism.

Decapitation and abdomen isolation of the pupae were performed using a razor blade. The wounds were then sealed with molten paraffin.

Chemicals. - E was purchased from Simes (Milano, Italy) and [1 $\left.\alpha, 2 \alpha(\mathrm{N})-\left({ }^{3} \mathrm{H}\right)\right]$ cholesterol (specific activity $60 \mathrm{Ci} / \mathrm{mmol}$ ) from CEA (Saclay, France).

Tritiated $\mathrm{E}$ (specific activity $100 \mathrm{Ci} / \mathrm{mmol}$ ) was prepared enzymatically from $\left(22,23,24-{ }^{3} \mathrm{H}\right)$ 2-deoxyecdysone (gift of Dr Hetru, Strasbourg) by incubation with Locusta Malpighian tubules (Modde et al., 1984).

Injections. - All the injections were performed laterally between the second and the third abdominal segments using a $10 \mu$ syringe. $E$ and/or $\left({ }^{3} \mathrm{H}\right) \mathrm{E}(1 \mu \mathrm{Ci} /$ animal $)$ were injected in $5 \mu \mathrm{l}$ of a buffered Lepidoptera saline (Weevers, 1966) as a single injection. For $\left({ }^{3} \mathrm{H}\right)$ cholesterol labelling experiments, cholesterol $(50 \mu \mathrm{Ci} /$ animal) was injected simultaneously with $0.5 \mu \mathrm{g}$. For this, both products were emulsified in $0.2 \%$ aqueous Tween 80 solution by extensive sonication just before the injection (Beydon et al., 1981). Control specimens were injected with buffered Lepidoptera saline or Tween 80 emulsion, depending on the experiments. The injection puncture was sealed with molten paraffin. Operated and 
control animals were sacrificed at different times after treatment and frozen at $-80^{\circ} \mathrm{C}$ until use.

Sample preparation for HPLC analysis. - Animals were homogenized in water : chloroform (1/1). Cholesterol was recovered in the chloroform phase; ecdysteroids present in the water phase were processed for HPLC analysis as previously described (Lafont et al., 1982). $10 \mu \mathrm{g}$ of muristerone A (a phytoecdysteroid not present in Pieris brassicae) were added before extraction in order to estimate the ecdysteroid recovery along this procedure.

The HPLC analysis was performed on a reverse-phase column (Zorbax ODS) eluted with a linear gradient of acetonitrile $(8-40 \%$ in $60 \mathrm{~min}$ ) in $20 \mathrm{mM}$ Tris$\mathrm{HClO}_{4}$ buffer, $\mathrm{pH} 7.5$ at a flow rate of $1 \mathrm{ml} / \mathrm{min}$. Solvents were purchased from Rathburn (HPLC grade); pump (module 848) and preprogrammed gradient former were from Dupont.

The amount of muristerone A was determined by UV monitoring at $254 \mathrm{~nm}$ after the whole extraction and HPLC analysis procedures. The ecdysteroid levels in the biological samples were determined by HPLC (Lafont et al., 1982).

The incorporation rate of cholesterol into ecdysteroids $(R)$ was calculated according to Beydon et al. (1981) and Beydon and Lafont (1983) as :

$$
\mathrm{R}=\frac{\mathrm{c}}{\mathrm{rT}}
$$

where $\mathrm{c}$ is the radioactivity in a given compound, $\mathrm{r}$ is the recovery after extraction and HPLC analysis and $T$ is the radioactivity of the injected cholesterol.

TABLE 1

Effects of different doses of injected ecdysone or 20-hydroxyecdysone on diapause termination.

\begin{tabular}{|c|c|c|c|c|}
\hline & $\begin{array}{l}\text { Injected ecdysone } \\
\text { in ng/pupae }\end{array}$ & $\begin{array}{l}\text { Surviving } \\
\text { animals }\end{array}$ & $\begin{array}{l}\text { Developing } \\
\text { animals }\end{array}$ & $\begin{array}{l}\text { Duration of } \\
\text { development in days }\end{array}$ \\
\hline Ecdysone & $\begin{array}{r}0 \\
25 \\
50 \\
100 \\
200 \\
500 \\
1000 \\
2000\end{array}$ & $\begin{array}{r}10 \\
10 \\
10 \\
10 \\
8 \\
8 \\
10 \\
9\end{array}$ & $\begin{array}{r}0 \\
0 \\
0 \\
9 \\
8 \\
8 \\
10 \\
9\end{array}$ & $\begin{array}{c}- \\
- \\
- \\
32.5+3.0 \\
28.3+4.0 \\
24.1+0.3 \\
24.0 \\
24.0\end{array}$ \\
\hline $\begin{array}{l}\text { 20-Hydroxy } \\
\text { ecdysone }\end{array}$ & $\begin{array}{r}0 \\
25 \\
50 \\
100 \\
200 \\
500 \\
1000 \\
2000\end{array}$ & $\begin{array}{r}10 \\
10 \\
9 \\
8 \\
8 \\
7 \\
4 \\
10\end{array}$ & $\begin{array}{c}0 \\
0 \\
0 \\
4 \\
7 \\
7 \\
4 \\
10^{*}\end{array}$ & $\begin{array}{c}- \\
- \\
- \\
35.5+2.8 \\
32.7+0.4 \\
26.6+3.5 \\
24.0 \\
-\end{array}$ \\
\hline
\end{tabular}

The hormone was given as a single injection in $5 \mu$ l of Lepidoptera saline buffer ; control animals injected with buffer alone never developed ; 10 animals were injected in all experiments. The duration of development (last column) represents the delay between the injection and adult eclosion; these experiments were performed at $15^{\circ} \mathrm{C}$; at this temperature the duration of direct development is 23 days.

* : pupae injected with $2000 \mathrm{ng}$ of 20-hydroxyecdysone developed but were unable to exuviate : this is characteristic of hyperecdysonism. 


\section{Results.}

Diapause termination after ecdysone or 20-hydroxyecdysone injection.

Diapausing pupae were injected with increasing amounts of $E$ or $20 \mathrm{E}$. Table 1 shows that diapause termination was dose-dependent in both cases. A minimal dose of $100 \mathrm{ng} /$ animal was required to induce development. However in these conditions the delay from injection to adult eclosion was highly variable. A dose of $500 \mathrm{ng} /$ animal was found to be in both cases the minimal dose inducing a synchronous development. Doses of $2000 \mathrm{ng}$ of $20 \mathrm{E}$ led to hyperecdysonism, characterized by a failure of exuviation (Williams, 1968). None of the untreated animals, and none of control pupae receiving $5 \mu \mathrm{l}$ of Lepidoptera saline buffer terminated diapause. In all the further experiments the termination of diapause was induced by injection of $500 \mathrm{ng} \mathrm{E}$ per animal (ca. $1.25 \mu \mathrm{g} / \mathrm{g}$ live weight),

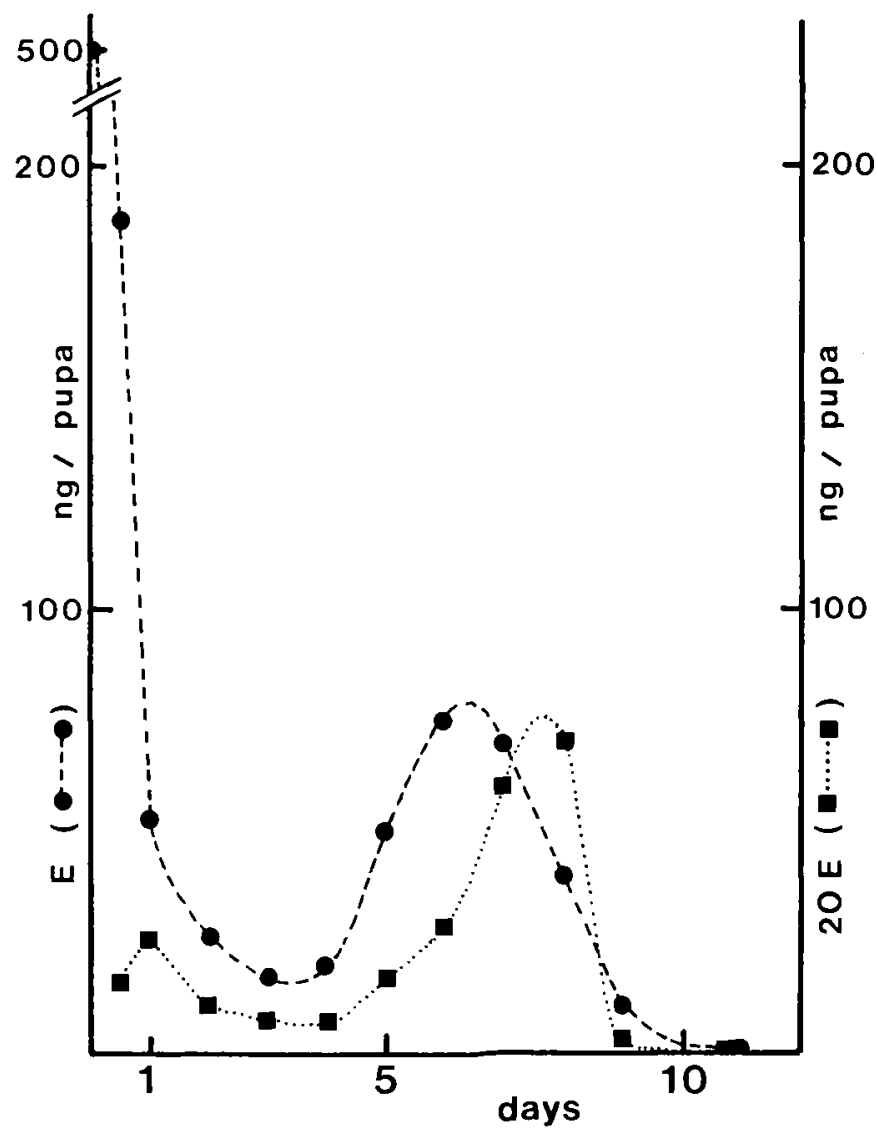

FIG. 1. - Ecdysone (- ) and 20-hydroxyecdysone ( various times after the injection of $500 \mathrm{ng}$ of ecdysone.

The amounts of $E$ and $20 \mathrm{E}$ per animal were determined by HPLC analysis ; each point is the mean value of three individual determinations. 
because it is the lowest dose of this hormone which leads to a synchronous development.

Ecdysone and 20-hydroxyecdysone leve/s in pupae treated with ecdysone.

Diapausing pupae were injected with $500 \mathrm{ng}$ of ecdysone; the animals were then sacrificed at different times following injection, and $E$ and $20 E$ levels were determined by HPLC analysis (fig. 1).

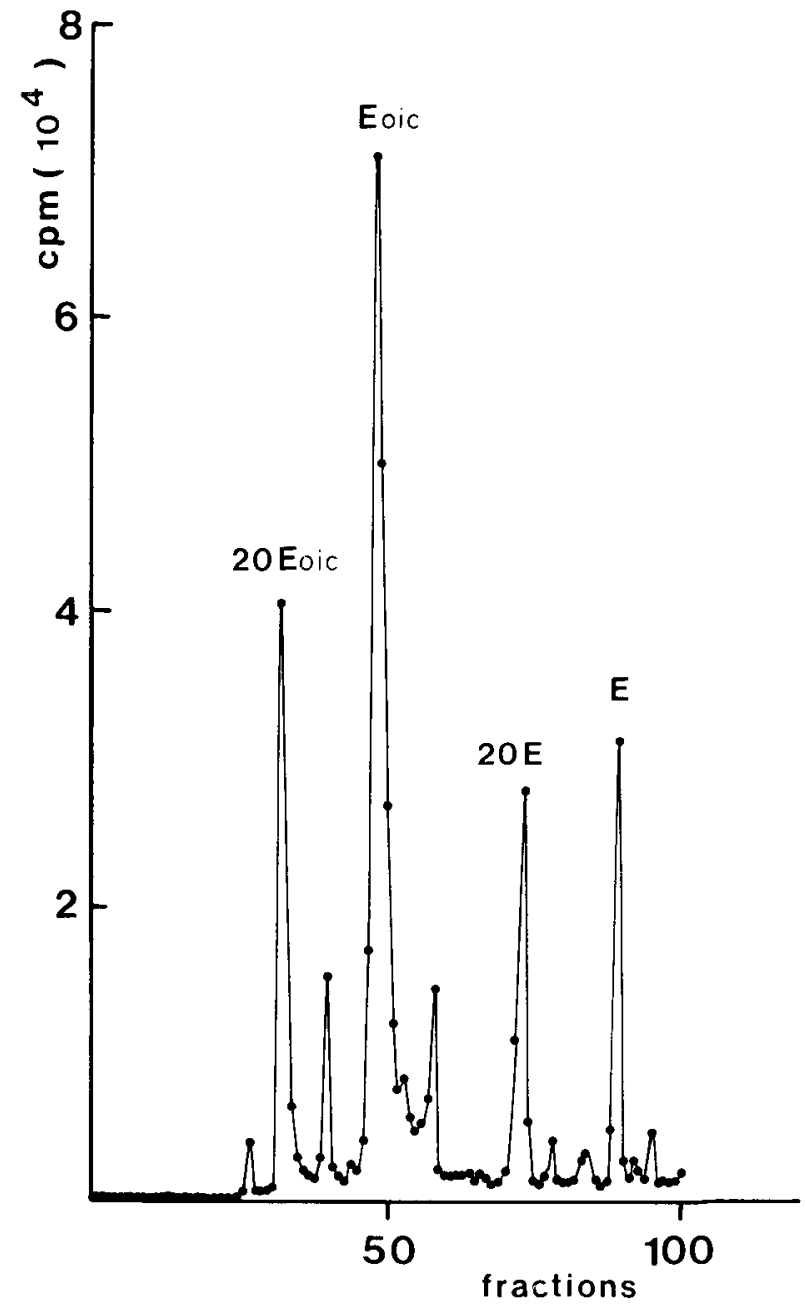

FIG. 2. - Pattern of labelled ecdysteroids obtained after $\left.{ }^{3} \mathrm{H}\right)$ ecdysone injection in ecdysonestimulated pupae.

Diapausing pupae were injected simultaneously with $1 \mu \mathrm{Ci}$ of tritiated ecdysone and $500 \mathrm{ng}$ of ecdysone, and sacrificed in this case $24 \mathrm{hrs}$ later. Purified extract was analyzed under the following conditions : HPLC column Zorbax ODS, $250 \mathrm{~mm}$ long, $(4.6 \mathrm{~mm}$ i.d.) ; elution with a linear gradient $(60 \mathrm{~min}), 8 \%$ to $40 \%$ acetonitrile in Tris-perchlorate buffer $20 \mathrm{mM}, \mathrm{pH} 7.5$; 0.4 min fractions were collected and counted in mini scintillation vials with $1.5 \mathrm{ml}$ scintillation cocktail.

E : ecdysone ; $20 \mathrm{E}$ : 20-hydroxyecdysone ; Eoic : ecdysonoic acid ; 20 Eoic : 20-hydroxyecdysonoic acid. 
E rapidly decreased from treated pupae ; only half of the injected dose was recovered in the animal 12 hours after injection, and after 2 days we detected only $25 \mathrm{ng}$ of $\mathrm{E} /$ animal. The level of $\mathrm{E}$ remained very low during the following days, but increased from day 5 to day 7 where it reached $85 \mathrm{ng} /$ animal. E became undetectable at day 9. A delayed peak of $20 \mathrm{E}$ was also observed at day 7-8 (fig. 1). Several hypotheses can be drawn to explain the increase in $E$ levels beginning 5 days after treatment :

(1) a neosynthesis of ecdysone occurs in ecdysone-stimulated pupae ; this can be checked by $\left({ }^{3} \mathrm{H}\right)$ cholesterol labelling experiments ;

(2) exogenous ecdysone either is recycled or it induces a mobilization of ecdysteroid conjugates or metabolites, produced and stored during e.g. the prepupal stage or the early beginning of diapause. In fact, injected E or $20 \mathrm{E}$ in late last larval instar larvae are rapidly converted into ecdysonoic acids or conjugates of 3-epimers which in no case can be converted back to the parent compounds. This rules out the possibility of recycling of endogenous conjugates. The possible recycling of injected ecdysone was tested by long term labelling experiments with $\left({ }^{3} \mathrm{H}\right)$ ecdysone.

\section{Ecdysone catabolism in ecdysone-stimulated diapausing pupae.}

$\mathrm{E}\left(500 \mathrm{ng} /\right.$ animal) and $\left({ }^{3} \mathrm{H}\right) \mathrm{E}(1 \mu \mathrm{Ci}$ /animal) were injected simultaneously in diapausing animals, in order to study the fate of the injected hormone; the pattern of labelled ecdysteroids was then analyzed by HPLC at several times after the injection. Figure 2 shows the pattern of labelled metabolites recovered $24 \mathrm{hrs}$ after the injection; it is observed that the major products are ecdysonoic- and 20-hydroxyecdysonoic acids. Thus the metabolism of injected $E$ is highly comparable to that previously reported in aged developing pupae ( 8 days, see Beydon et al., 1981). Figure 3 shows the fate of $\left({ }^{3} \mathrm{H}\right) \mathrm{E}$ and $\left({ }^{3} \mathrm{H}\right) 20 \mathrm{E}$ expressed as a

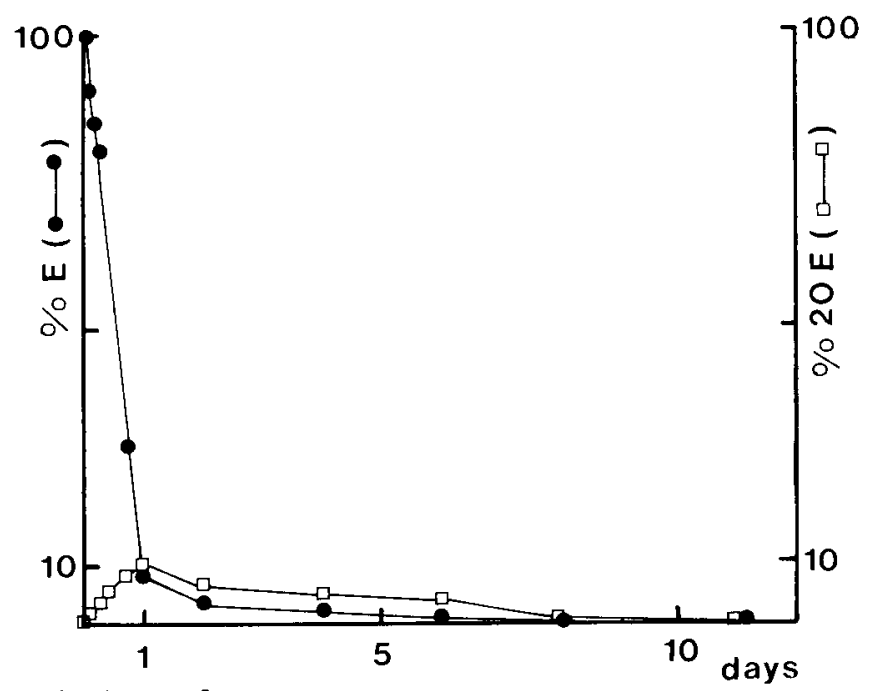

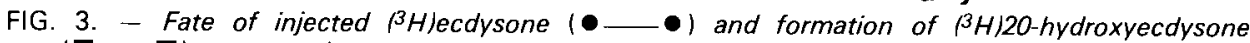

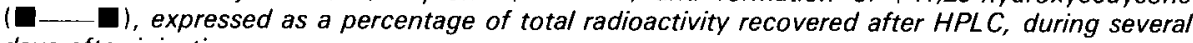
days after injection. 
percentage of total radioactivity recovered after HPLC analysis. We observed a sharp decrease of radiolabelled $E$ : half of the radiolabelled hormone was already metabolized after 12-14 hrs and less than $5 \%$ was still detected two days after the injection. We observed in parallel the formation of a low proportion of $\left({ }^{3} \mathrm{H}\right) 20 \mathrm{E}$ : $24 \mathrm{hrs}$ after the injection only $10 \%$ of the total radioactivity was recovered as $20 \mathrm{E}$. The bulk of radioactivity consisted in two major polar products : ecdysonoic- and 20-hydroxyecdysonoic acids. No increase in radiolabelled $E$ or $20 \mathrm{E}$ could be detected on day 5 or after; we can then rule out the possibility that the increase in E level observed by HPLC analysis is due to a recycling of the injected hormone: in this case we would have observed a corresponding increase in the radioactivity of $E$ and $20 \mathrm{E}$.

It should be noticed also that only $10 \%$ (at most) of the injected $E$ was recovered as $20 \mathrm{E}, 24 \mathrm{hrs}$ after the injection: this would correspond to the presence at this time of only $50 \mathrm{ng}$ of $20 \mathrm{E} /$ animal. Nevertheless, this amount decreased rather slowly during the following days.

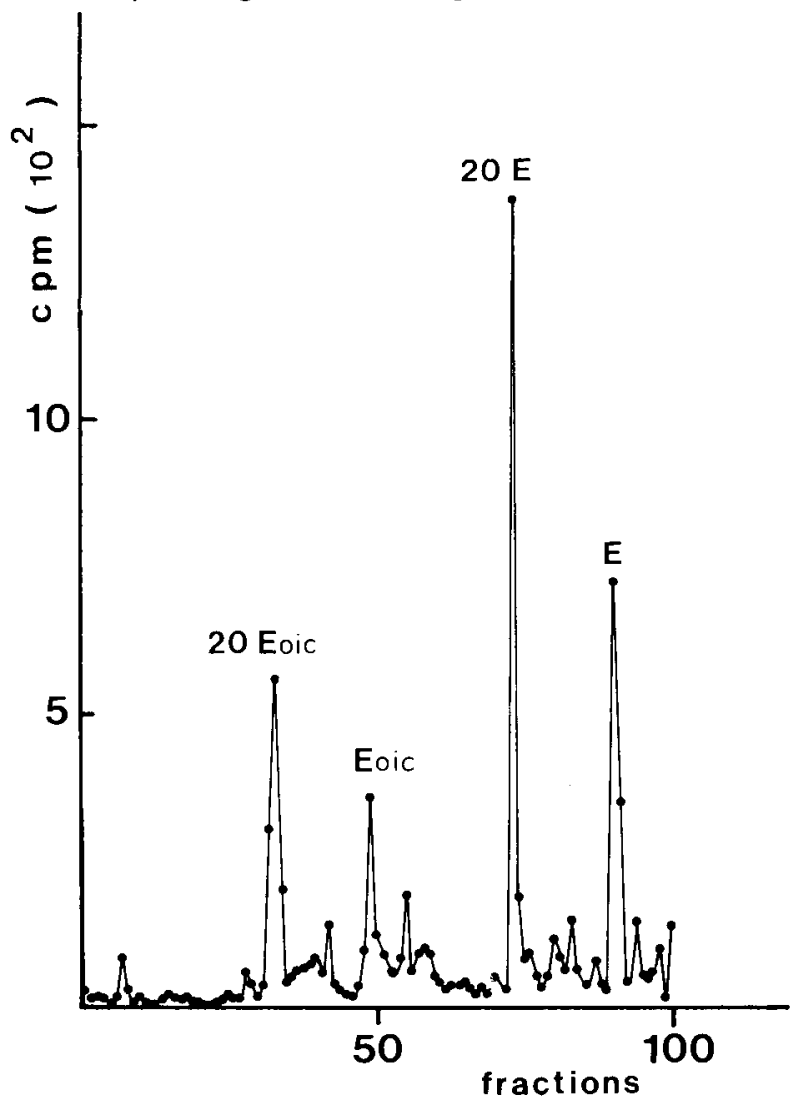

FIG. 4. - Pattern of labelled ecdysteroids obtained after $\left.{ }^{3} \mathrm{H}\right)$ cholesterol injection in ecdysonestimulated diapausing pupae.

Animals were injected simultaneously with $50 \mu \mathrm{Ci}$ of $(3 \mathrm{H})$ cholesterol and $500 \mathrm{ng}$ of ecdysone, and extracted 9 days later. HPLC conditions were the same as in figure 2 . Note the appearance at this time of polar products : ecdysonoic (Eoic) and 20-hydroxyecdysonoic (20-Eoic) acids.

E : ecdysone ; $20 \mathrm{E}$ : 20-hydroxyecdysone. 


\section{$\left({ }^{3} \mathrm{H}\right)$ cholesterol labelling experiments.}

In this series of experiments $\left({ }^{3} \mathrm{H}\right)$ cholesterol $(50 \mu \mathrm{Ci} /$ animal) was injected simultaneously with E $(500 \mathrm{ng} /$ animal). The incorporation of cholesterol into ecdysteroids was then followed during several days after the injection in order to detect any biosynthesis of tritiated ecdysteroids in these animals.

Control animals receiving only $\left({ }^{3} \mathrm{H}\right)$ cholesterol never developed and never showed any incorporation of cholesterol even 12 days after the injection.

In animals injected with both $\left({ }^{3} \mathrm{H}\right)$ cholesterol and $500 \mathrm{ng} \mathrm{E}$, a synthesis of $\left({ }^{3} \mathrm{H}\right) \mathrm{E}$ was detected on day 5 following injection; $\left({ }^{3} \mathrm{H}\right) \mathrm{E}$ was then hydroxylated into $\left({ }^{3} \mathrm{H}\right) 20 \mathrm{E}$ : inactivation compounds e.g. ecdysonoic- and 20 -hydroxyecdysonoic acids appeared afterwards (day 8) until becoming the major products (fig. 4).

Figure 5 shows the evolution of $\left({ }^{3} \mathrm{H}\right)$ cholesterol incorporation into $E$ and $20 \mathrm{E}$, and in total ecdysteroids (both hormones and their inactivation products) during the 15 days following the injection. The incorporation of cholesterol began on day 5 and reached its maximal value $(0.062 \%)$ on day 7 ; the incorporation into $E$

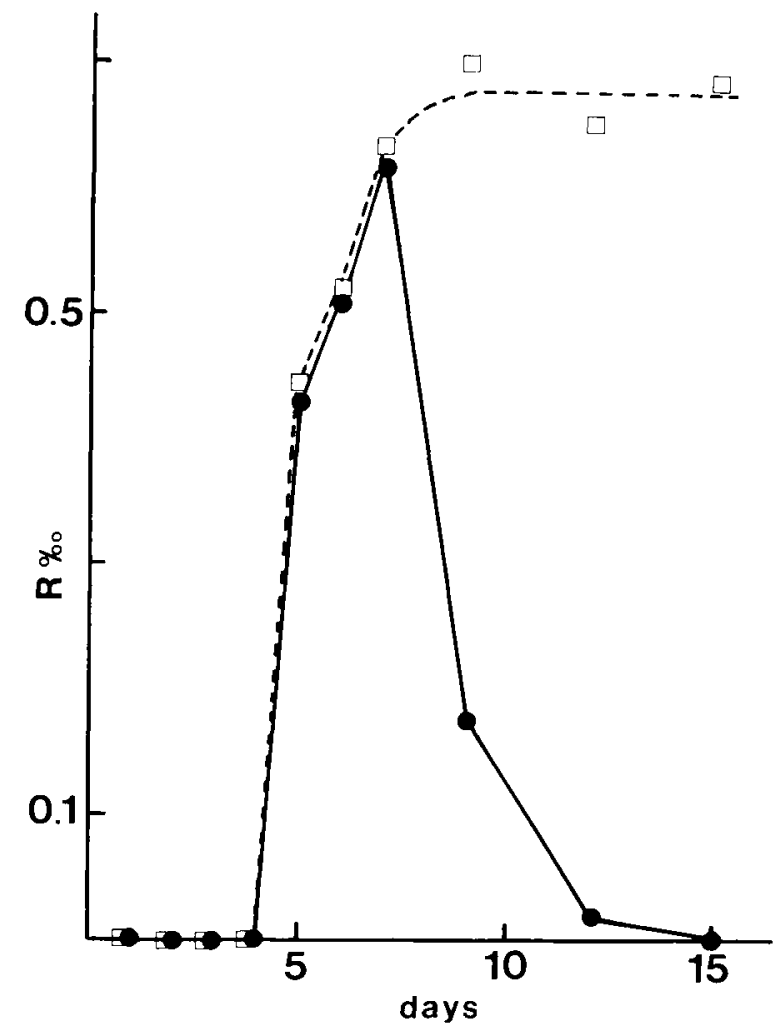

FIG. 5. - Incorporation rate (R) of ${ }^{3} \mathrm{H} /$ cholesterol into ecdysone + 20-hydroxyecdysone (- $\bullet$ ), and into total ecdvsteroids ( $\square-\square)$ at various times after the iniection of $50 \mu \mathrm{Ci}$ of $\mathrm{\beta}^{3} \mathrm{H}$ ) cholesterol and $500 \mathrm{ng}$ of ecdysone in diapausing pupae.

The maximal incorporation rate $(R$, see section Material and Methods) into ecdysone and 20hydroxyecdysone was $0.062 \%$. 
and $20 \mathrm{E}$ decreased until day 12 where it became undetectable. At this time all the radioactivity was recovered into inactivation products originating from the hormones present at day 7 . The incorporation rate into total ecdysteroids also reached its maximal value on day 7 and then remained stable; this has to be related to the fact that pupae constitute a closed system where no excretion occurs.

The cholesterol incorporation into ecdysteroids gives evidence for de novo synthesis of ecdysone i.e. that injected $E$ can promote a reactivation of the endocrine system.

The cholesterol pool in a diapausing pupa is approximately $150 \mu \mathrm{g}$ or $0.38 \mu \mathrm{mole} /$ animal (Beydon, unpublished data); thus a $0.062 \%$ incorporation (maximal value) of cholesterol into $E$ and $20 \mathrm{E}$ would correspond to the formation of $0.38 \times 6.210^{-4}=2.310^{-4} \mu$ moles or $115 \mathrm{ng}$ ecdysteroid per pupa. The HPLC determination gives at this time (7 days) $130 \mathrm{ng}$ of $\mathrm{E}$ and $20 \mathrm{E}$ per animal. These two values being in the same range, we can assume that the rise in $E$ and $20 \mathrm{E}$ levels at this time is due for the major part to the neosynthesis of ecdysone.

We further investigated whether the brain was necessary for the stimulatory action of exogenous $E$.

\section{Decapitated animals.}

Decapitated diapausing animals receiving $500 \mathrm{ng}$ of $\mathrm{E}$ all resumed their development as whole treated pupae, but we observed that the adult eclosion occurred in a more asynchronous manner (from 19 to 25 days after the injection).

We investigated whether the decapitated pupae were able to neosynthesize ecdysteroids. For this the same $\left({ }^{3} \mathrm{H}\right)$ cholesterol labelling experiments were performed in headless pupae. We observed indeed a neosynthesis of $E$ beginning 5 days after the injection (not shown); the incorporation rate was at this time $0.02 \%$, which is lower than in entire animals.

This means that injected $E$ can act in the absence of the brain to reactivate the biosynthesis of endogenous $E$.

\section{Isolated abdomens.}

Isolated abdomens from diapausing pupae were immediately injected with $500 \mathrm{ng}$ of $\mathrm{E}$; we observed that all of them developed : they were morphologically undistinguishable from adult abdomens, according to black pigmentation and cuticular structures formation.

We studied the metabolism of $\left({ }^{3} \mathrm{H}\right) \mathrm{E}$ in these ecdysone-stimulated abdomens. Figure 6 shows the fate of $\left({ }^{3} \mathrm{H}\right) \mathrm{E}$ and $\left({ }^{3} \mathrm{H}\right) 20 \mathrm{E}$ during six days following the injection. The catabolism of $\left({ }^{3} \mathrm{H}\right) \mathrm{E}$ was rather fast during the first $24 \mathrm{hrs}$ but then much slower ; in parallel about $5 \%$ were hydroxylated into $20 \mathrm{E}$ and this remained very stable during the following days.

These ecdysone-stimulated abdomens however never showed any incorporation of $\left({ }^{3} \mathrm{H}\right)$ cholesterol into ecdysteroids. Thus in the absence of head and prothorax, no neosynthesis of E occurred. 


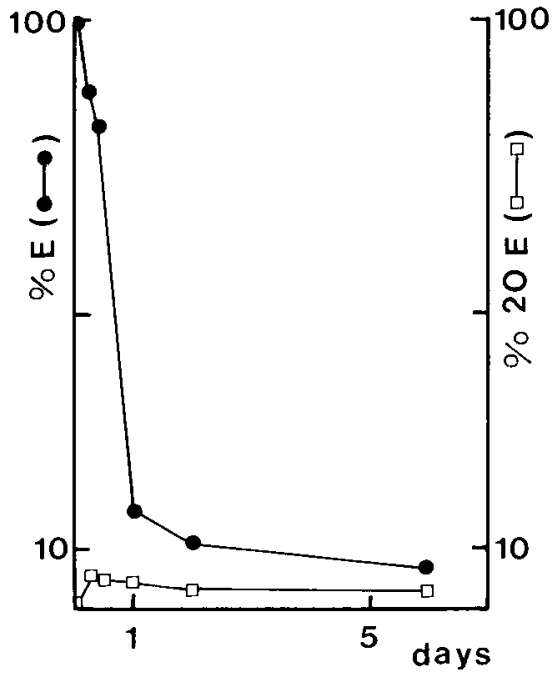

FIG. 6. - Fate of $\left({ }^{3} \mathrm{H}\right)$ ecdysone (-_ ) and ${ }^{3} \mathrm{H} / 20$-hydroxyecdysone $(\square-\square)$, expressed as a percentage of total radioactivity recovered after HPLC, in isolated abdomens of diapausing pupae. Abdomens were injected just after isolation with both $500 \mathrm{ng}$ of ecdysone and $1 \mu \mathrm{Ci}$ of $\left({ }^{3} \mathrm{H}\right)$ ecdysone; they were then sacrificed and extracted at various times after treatment.

\section{Discussion.}

Many authors have previously established that by injecting $E$ or $20 E$ it was possible to induce adult development in diapausing pupae of Lepidoptera (Williams, 1968 ; Bradfield and Denlinger, 1980 ; Bodnaryk, 1985). However little attention has been paid to the mechanism of action of the injected hormone. Indeed, two different hypotheses can be drawn : (1) the injected hormone is able by itself to elicit adult differentiation and (2) the injected hormone triggers the reactivation of the neuroendocrine system of the animal which will thereafter synthesize endogenous ecdysteroids responsible of the onset of development. Of course, the two hypotheses are not mutually exclusive.

In the case of Pieris diapausing pupae the minimal dose of ecdysone required for inducing synchronous development in $100 \%$ of the pupae was $500 \mathrm{ng} /$ animal.

In order to test the hypothesis (1), we injected ecdysone into isolated abdomens (+ meso- and metathorax). It had previously been shown that abdomens removed from non-diapausing Pieris pupae were unable to synthesize ecdysone from cholesterol de novo (Beydon et al., 1981) and this was confirmed in the present study with diapausing isolated abdomens. Injected abdomens developed adult structures (e.g. pigmented scales), and this provides evidence that the injected hormone is able by itself to evoke adult differentiation. Due to the lack of any $E$ synthesis in this system, it was possible to calculate $E$ and $20 E$ levels in isolated abdomens after an injection of $\left({ }^{3} \mathrm{H}\right) \mathrm{E}$ and $500 \mathrm{ng}$ of $\mathrm{E}$. It was found that $20 \mathrm{E}$ levels remained quite constant for several days at $25 \mathrm{ng} / \mathrm{abdomen}$ (5\% of the injected radioactivityi. This low value seems however sufficient to evoke adult development. In fact, this situation is very similar to that observed in abdomens from non-diapausing Pieris pupae isolated on day 3 after larval-pupal ecdysis (i.e. 2 days before the large 20E peak), which undergo adult development (Claret et al., 1977). From our data, we may conclude that hypothesis (1) is still 
valid : the injected hormone is by itself able to promote adult differentiation of pupal tissues.

$E$ and $\left({ }^{3} \mathrm{H}\right) \mathrm{E}$ injected into whole pupae were rapidly converted into inactivation products (fig. 1); 24 hours after injection only $10 \%$ of the injected hormone was recovered as $20 \mathrm{E}$ and this proportion decreases thereafter; this represents $50 \mathrm{ng}$ of active moulting hormone present in the animal at this time, a value which is far below the maximal amount of $20 \mathrm{E}$ occurring in non-diapausing Pieris pupae (250 ng/animal) (Beydon et al., 1981). This low but sustained amount could nevertheless be involved in the initiation of adult development, as discussed above. On the other hand we observed an important incorporation of $\left({ }^{3} \mathrm{H}\right)$ cholesterol into ecdysteroids five days after $\mathrm{E}$ injection. Since this synthesis is not observed in isolated abdomens, the simplest explanation (but we do not consider this as an absolute proof) is that it is performed by pupal prothoracic glands. The neosynthesized ecdysone is probably involved in the control of adult cuticle synthesis. This assumption is based on experiments with isolated abdomens of non-diapausing pupae at day 3 , where adult differentiation was observed, but adult cuticle synthesis was much reduced and abnormal, unless extra-ecdysone was injected (Cassier et al., 1980).

Therefore we can conclude that the injected $E$ exerts a dual effect in entire animals : (1) it triggers directly adult differentiation of target organs and (2) it is able to evoke a delayed ecdysone synthesis probably involved in adult cuticle synthesis and synchronism of development.

Concerning the mechanism by which the injected hormone is able to activate the ecdysone-synthesis machinery, two points are worth mentioning : (1) the fact that it takes place in headless pupae, i.e. in the absence of the brain neuroendocrine system and (2) the rather long delay ( 5 days) observed before the reactivation of $E$ synthesis.

(1) We observed that exogenous $E$ induces the onset of development in headless pupae and particularly the reactivation of $E$ synthesis just like in whole animals; thus the brain neuroendocrine system does not seem necessary here for the action of injected $E$ on endogenous $E$ neosynthesis. McDaniel (1979) reported that headless diapausing pupae of Hyalophora cecropia were able to develop when returned to warm temperatures after a long period of chilling, and that they presented in parallel a reactivation of ecdysone production. The fact that diapausing pupae can resume development in the absence of the brain appears in fact rather common in Lepidoptera : it has also been reported for example in Heliothis zea (Meola and Adkisson, 1977) and Manduca sexta (Safranek and Williams, 1980). Thus the regulation of $E$ production in several species of Lepidoptera may be different from the classical scheme involving the brain action on ecdysone synthesis.

(2) The long delay ( 5 days) required to induce $E$ production might be due to a general reactivation of all cellular metabolism pathways which are turned down in a diapausing pupa. Indeed a similar latency (6 days) was observed for the rise of oxygen consumption which parallels the reinitiation of adult development after E injection in Pieris brassicae diapausing pupae (Guillet and Fourche, 1976). In addition, the effect of $E$ on the reactivation of $E$ biosynthesis might involve a 
multistep sequence of events. In this sense, it should be considered that cholesterol may not be the immediate suitable precursor of ecdysteroids (Bollenbacher et al., 1977), and that $E$ production may require intermediate stimulatory factors as recently reported in Manduca sexta (Gruetzmacher et al., 1984a, 1984b ; Watson et al., 1985).

The fact that exogenous $E$ can exert a stimulatory effect on $E$ production apparently contradicts previous results obtained in normal developing pupae, in which it has been shown that $E$ and $20 E$ inhibited $E$ production when injected during the ecdysteroid biosynthesis period (Beydon and Lafont, 1983). This feedback inhibition also occurred in headless non-diapausing pupae, suggesting that $E$ acts independently of the brain. Nevertheless it should be noticed that this inhibitory action appears very rapidly (a few hours after injection), whereas the stimulatory effect of exogenous $E$ in diapausing pupae is long-delayed. The fact that the physiological states, particularly the endocrine context, are very different in the two cases should certainly be taken into account to explain these two opposite effects of $E$ injection on endogenous $E$ production.

Reçu en juin 1986.

Accepté en septembre 1986.

Acknowledgements. - This work was supported by grants from CNRS and INRA.

Résumé. Mécanisme d'action de l'ecdysone exogène dans la levée de la diapause nymphale chez Pieris brassicae. Mise en évidence d'une action stimulatrice sur la synthèse $d^{\prime} e c d y s o n e$ de novo.

II est possible chez des chrysalides de Pieris brassicae de lever expérimentalement la diapause par injection d'ecdysone; une dose de $500 \mathrm{ng} /$ animal suffit pour obtenir un développement synchrone des animaux. Des expériences ont été réalisées afin de déterminer si l'hormone injectée agit directement sur les tissus cibles, provoquant leur développement, et/ou si elle provoque une réactivation du système neuroendocrine, déclenchant ainsi une néosynthèse d'ecdysone. Nous avons montré que l'ecdysone injectée à des animaux entiers ou décapités induit, après un délai de 5 jours, une reprise de la synthèse d'ecdysone: l'hormone exogène exerce donc une action stimulatrice sur le système de biosynthèse, et ceci indépendamment du cerveau. Par ailleurs, des abdomens isolés de chrysalides diapausantes se développent également en réponse à l'injection de la même dose d'hormone, mais ils ne montrent aucune synthèse d'ectystéroïdes : ceci suggère que l'ecdysone injectée possède parallèlement une action morphogénétique directe.

\section{References}

BERGAMASCO R., HORN D. H. S., 1980. The biological activities of ecdysteroids and ecdysteroid analogues, 299-324. in HOFFMANN J.A. Progress in ecdysone research Elsevier/North Holland, Amsterdam.

BEYDON P., CLARET J., PORCHERON P., LAFONT R., 1981. Biosynthesis and inactivation of ecdysone during the pupal-adult development of the cabbage butterfly, Pieris brassicae $\mathrm{L}$. Steroids, 38, 633-649.

BEYDON P., LAFONT R., 1983. Feedback inhibition of ecdysone production by 20-hydroxyecdysone in Pieris brassicae pupae. J. Insect Physiol., 29, 529-533.

BODNARYK R. P., 1985. Ecdysone levels during post-diapause development and 20-hydroxyecdysone-induced development in male pupae of Mamestra configurata WLK. J. Insect Physiol., 31, 53-58.

BOLLENBACHER W. E., GALBRAITH M. N., GILBERT L. I., HORN D. H. S., 1977. In vitro 
metabolism of $3 \beta$-hydroxy, and $3 \beta, 14 \alpha$-dihydroxy-[3 $\alpha$-3H]-5 $\beta$-cholest-7-en-6-one by the prothoracic glands of Manduca sexta. Steroids, 29, 47-63.

BOLLENBACHER W. E., AGUI N., GRANGER N. A., GILBERT L. I., 1979. In vitro activation of insect prothoracic glands by the prothoracicotropic hormone. Proc. nat. Acad. Sci. USA, 76 , 5148-5152.

BRADFIELD IV J. Y., DENLINGER D. L., 1980. Diapause development in the tobacco hornworm : a role for ecdysone or juvenile hormone? Gen. comp. Endocrinol., 41, 101-107.

CASSIER P., BAEHR J. C., CARUELLE J. P., PORCHERON P., 1980. The integument and ecdysteroids : in vivo and in vitro studies, 235-346. In HOFFMANN J. A. Progress in ecdysone research. Elsevier/North Holland, Amsterdam.

CHINO H., SAKURAI S., OHTAKI T., IKEKAWA N., MIYAZAKI H., ISHIBASHI M., ABUKI H., 1974. Biosynthesis of $\alpha$-ecdysone by prothoracic glands in vitro. Science, 183, 529-530.

CLARET J., 1972. Période de sensibilité des chenilles de Pieris brassicae à la photopériode contrôlant la diapause. C. R. Acad. Sci. Paris, 274, 1055-1058.

CLARET J., DRAY F., PORCHERON P., 1977. Critical periods and ecdysone titers in the pupae of Pieris brassicae. Experientia, 33, 1389-1390.

GRUETZMACHER M. C., GILBERT L. I., GRANGER N. A., GOODMAN W., BOLLENBACHER W. E., 1984a. The effect of juvenile hormone on prothoracic gland function during larval-pupal development of Manduca sexta ; in situ and in vitro analysis. J. Insect Physiol., 30, 331-340.

GRUETZMACHER M. C., GILBERT L. I., BOLLENBACHER W. E., 1984b. Indirect stimulation of the prothoracic glands of Manduca sexta by juvenile hormone : evidence for a fat body stimulatory factor. J. Insect. Physiol, 30, 771-778.

GUILLET C., FOURCHE J., 1976. Les modifications du métabolisme énergétique lors de la levée de diapause par injection d' $\alpha$-ecdysone. Bull. Biol. Fr. Belg., 110, 31-34.

KING D. S., SIDALL J. B., 1969. Conversion of $\alpha$-ecdysone to $\beta$-ecdysone by crustaceans and insects. Nature, 221, 955-956.

KING D. S., BOLLENBACHER W. E., BORST D. W., VEDECKIS W. V., O'CONNOR J. D., ITTICHERIAH P. V., GILBERT L. I., 1974. The secretion of $\alpha$-ecdysone by the prothoracic glands of Manduca sexta in vitro. Proc. nat. Acad. Sci. USA., 71, 793-796.

LAFONT R., PENNETIER J. L., ANDRIANJAFINTRIMO M., CLARET J., MODDE J. F., BLAIS C., 1982. Sample processing for high-pressure liquid chromatography of ecdysteroids. $J$. Chromatog., 236, 137-149.

MCDANIEL C. N., 1979. Haemolymph ecdysone concentrations in Hyalophora cecropia pupae, dauer pupae and adults. J. Insect Physiol., 25, 143-145.

MEOLA R. W., ADKISSON P. L., 1977. Release of prothoracicotropic hormone and potentiation of development ability during diapause in the bollworm, Heliothis zea. J. Insect Physiol, 23. 683-688.

MODDE J. F., LAFONT R., HOFFMANN J. A., 1984. Ecdysone metabolism in Locusta migratoria larvae and adults. Int. J. Inver. Reprod. Devel., 7. 161-183.

SAFRANEK L., WILLIKAMS C. M., 1980. Studies of the prothoracicotropic hormone in the tobacco hornworm, Manduca sexta. Biol. Bull. mar. biol. Lab. (Woods Hole), 158, 141-153.

WATSON R. D., CIANCIO M. J., GUNNAR W. P., GILBERT L. I., BOLLENBACHER W. E., 1985. Regulation of insect prothoracic glands : existence of a haemolymph stimulatory factor in Manduca sexta. J. Insect Physiol., 31, 487-494.

WEEVERS R. D., 1966. A Lepidopteran saline: effects of inorganic cation concentrations on sensory, reflex and motor responses in a herbivorous insect. J. exp. Biol., 44, 163-175.

WILLIAMS C. M., 1946. Physiology of insect diapause : the role of the brain on the production and termination of pupal dormancy in the giant silkworm, Platysamia cecropia. Biol. Bull. mar. biol. Lab. (Woods Hole), 90, 234-243.

WILLIAMS C. M., 1947. Physiology of insect diapause. Il. Interaction between the pupal brain and prothoracic glands in the metamorphosis of the giant silkworm, Platysamia cecropia. Biol. Bull. mar. biol. Lab. (Woods Hole), 93, 89-98.

WILLIAMS C. M., 1952. Physiology of insect diapause. IV. The brain and prothoracic glands as an endocrine system in the cecropia silkworm. Biol. Bull. mar. biol. Lab. (Woods Hole), 103, 120-138.

WILLIAMS C. M., 1968. Ecdysone and ecdysone-analogues : their assay and action on diapausing pupae of the cynthia silkworm. Biol. Bull. mar. biol. Lab. (Woods Hole), 123, 344-355. 